\title{
Power Analysis for a Limited Bus Grid System with Distribution Generators
}

Nader Barsoum*, Christoper Asok, David Kwong and Clifford Thien Kit

Department of Electrical and Electronic Engineering, University Malaysia Sabah, Malaysia

\begin{abstract}
It has been recognized recently that when injecting renewable energy source power to a load buses which connected to some distributed feeders in a power grid system, a stability problem occurs particularly when having high fault duties that exceeding the circuit breaker ratings at some substations. In this paper an analysis of power flow, short circuit, stability and protection are given in detail to an example of limited 7-bus power grid system. Comparison are illustrated between power grid with and without distributed generators regarding bus voltages, fault currents, critical power angles, selected current transformers and over current relay settings in each bus. It discusses the selection of optimum slack bus in Gauss Seidel method, and shows that the system with distributed generators is more stable although the fault currents are higher than the system without distributed generators.
\end{abstract}

Keywords: Power grid; Bus voltages; Fault currents; Critical angle; Critical clearing time; Over current relay setting

\section{Introduction}

Recently, it is noticed that stability problem in power generation and relay setting problem occur due to high fault in distribution feeders which may probably cause by the injecting distribution generators in the load buses. Consumers like to use renewable energy sources installed in their home, factories, hospitals or moles and get a license to connect them to the power grid. The connection is found to be at distribution feeders which connected to the substation buses. This causes sometimes high fault duty and instability in the grid as well as exceeding the values of relay rate in some substations.

Normally the power system stability is analyzed in terms of bus voltages at steady-state and during fault and determined by critical clearing angle [1]. The phenomenon of bus voltage collapse due to a dynamic load in the power network is analyzed by simple power system model [2]. This voltage instability can also be analyzed by transferring the system model into a singular perturbation theory and solved by numerical investigation [3]. This voltage dropping at transient during fault leads to system disruption, which may be due to the maximum load power transfer from generation stations to load buses. Contingency analysis was presented in [4] and shows the post-contingency load flow and modified load flows in time domain. The contingency analysis and post-contingency analysis were used for long-term voltage stability; the credible contingencies are outages of transmission and generation facilities; in which a system must be able to withstand any single transmission or generation outage.

In this paper stability analysis is given for a simple limited 7-bus grid when a symmetrical 3-phase fault occurs at each bus. Comparisons between network with and without distribution generators are illustrated. This investigates the stability problem and avoided by calculating the critical angle and the corresponding critical clearing time to set up the over current relay at each bus.

The analysis started by load flow [5] using Gauss-Seidel method to calculate the optimum bus voltages by selecting suitable slack bus in the system. This is followed by calculating the fault current and the corresponding bus voltages at transient [6] considering the bus impedance matrix which is the inverse of the bus admittance matrix. Stability analysis is represented by calculating the critical angle in each bus based on the reactance values of the diagonal in the bus impedance matrix and the pre-fault bus voltages from load flow results with the transient voltages during fault from the short circuit results [7]. This is followed by the calculation of the critical clearing time assuming a constant moment of inertia in all turbine-generator system. This time is used for setting the relay and circuit breaker at each bus [8].

\section{Power Grid Model}

An example is taken for this analysis represented by a simple power network [8]. It consists of 7 buses; the first 2 are considered fusel fuel power stations referred to generating bus which generates $22 \mathrm{kV}$ each. The next 3 buses are transmission busses include 5 transformers and 4 transmission lines ( 3 medium with $275 \mathrm{kV}$ and one short with 132 $\mathrm{kV}$ ). The last 2 are the distribution buses, one for heavy industrial area and one for residential area. Bus 6 step down from $33 \mathrm{kV}$ to $11 \mathrm{kV}$ in 3 distributed feeders and then to $400 \mathrm{~V}$ to the shop moles. Bus 7 is connected to 20 distributed feeders with $6.6 \mathrm{kV}$ each then step down to $400 \mathrm{~V}$ to about 85 houses or flat units or shops in each feeder. These 2 bus loads are combined in one total load in each bus as shown in Figure 1. The consumers in these 2 areas are considering installing a renewable energy sources in each feeder, represented by distributed generators connected to the bus 6 and 7 giving the total power generation as shown in Figure 2. In order to investigate the process of calculation of power and line flow, the powers of the distributed generators (DG) are considered to be less than the power of loads in bus 6 and 7 .

The per unit values of power, admittance and impedance of all components in the grid can be calculated from its concept. These values are given in the network of Figure 3. Admittance and impedance

*Corresponding author: Nader Barsoum, Department of Electrical and Electronic Engineering, University Malaysia Sabah, Malaysia, Tel: 6088320000; E-mail: nader@ums.edu.my

Received June 28, 2017; Accepted August 27, 2017; Published August 31, 2017

Citation: Barsoum N, Asok C, Kwong D, Kit CT (2017) Power Analysis for a Limited Bus Grid System with Distribution Generators. Global J Technol Optim 8: 216. doi: 10.4172/2229-8711.1000216

Copyright: (c) 2017 Barsoum N, et al. This is an open-access article distributed under the terms of the Creative Commons Attribution License, which permits unrestricted use, distribution, and reproduction in any medium, provided the original author and source are credited. 


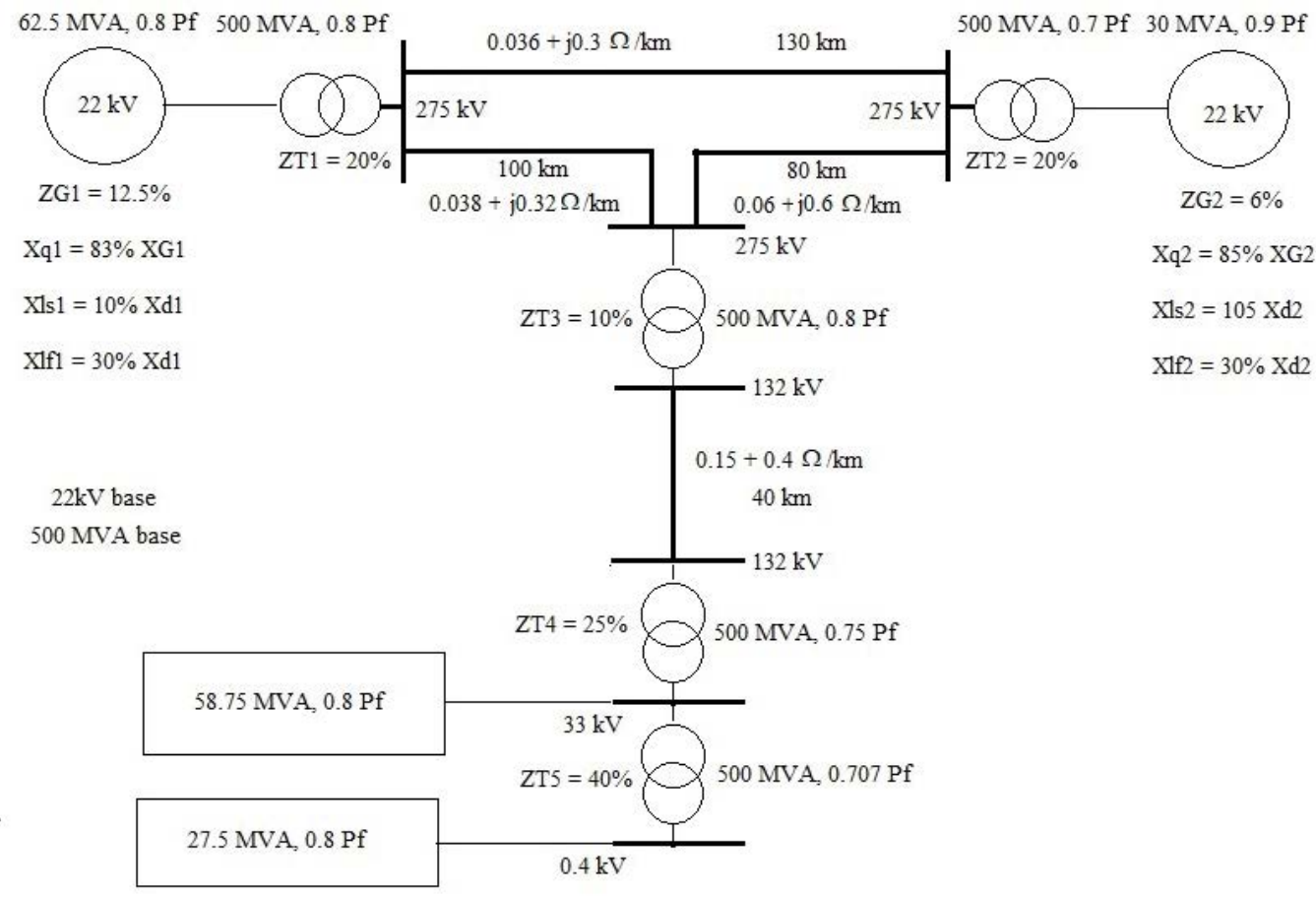

Figure 1: 7-bus Power Grid System without distributed generators.

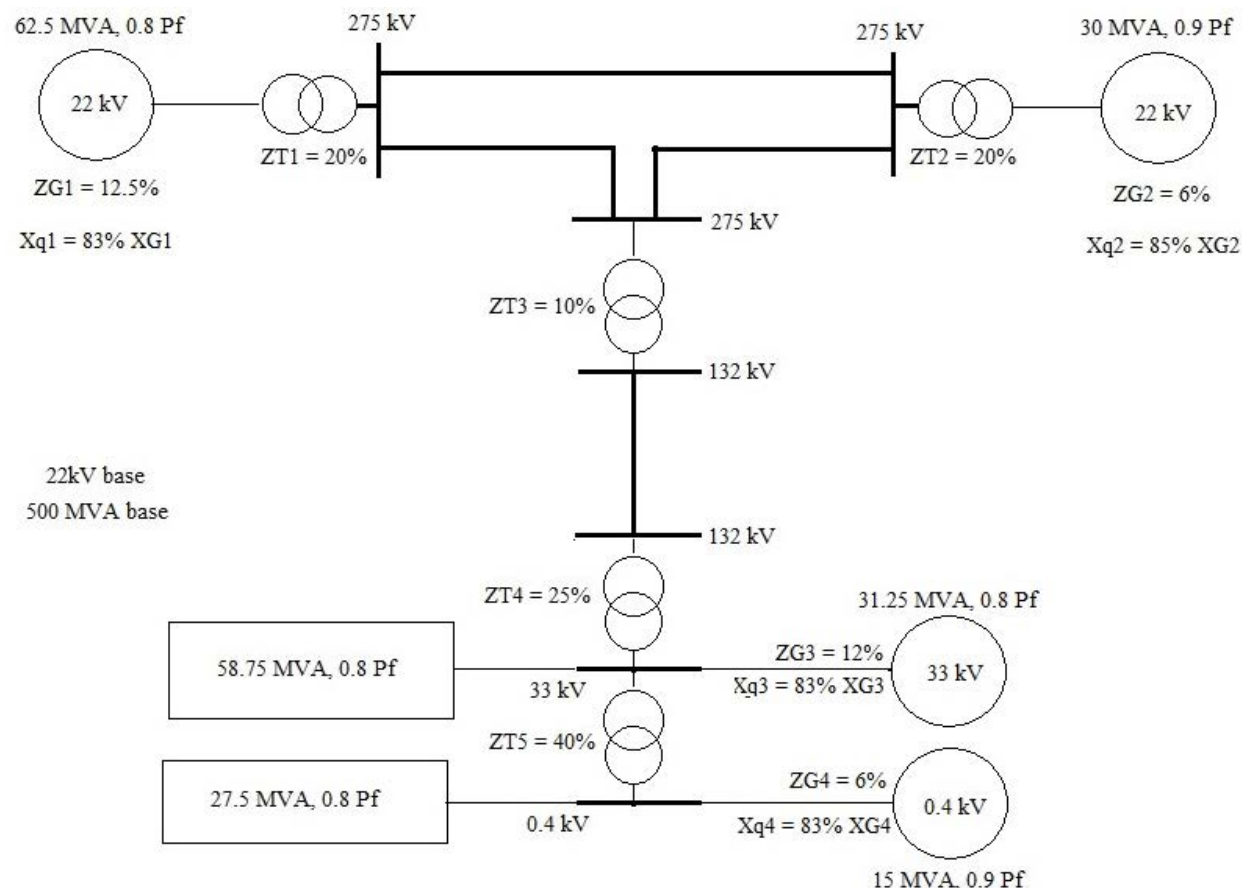

Figure 2: 7-bus Power Grid System with distributed generators.

matrices can be easily obtained, as in (1), (2), (3), (4).

Bus admittance matrix without distributed generator

Bus impedance matrix without distributed generator
Bus admittance matrix with distributed generator Bus impedance matrix with distributed generator

The only different in admittance matrix between (1) and (3) is found 
Citation: Barsoum N, Asok C, Kwong D, Kit CT (2017) Power Analysis for a Limited Bus Grid System with Distribution Generators. Global J Technol Optim 8: 216doi: 10.4172/2229-8711.1000216

Page 3 of 10

in the last 2 columns and rows, which are related to the distribution busses. While the inverse of admittance matrix shows quite different in impedance matrix between (2) and (4). Gauss-Seidel method is applied to this power network in both cases, with and without distributed generators. A numerical solution for the per unit bus voltages at steady-state is performed using MATLAB program for this system. The solution of voltage values in each bus is repeated 7 times for a selected slack bus with 1 per unit voltage. Table 1 shows the bus voltage values when selecting each bus as slack.

It can be seen from Table 1 that the realistic values of voltages at load buses 6 and 7 are smaller than the values of generating bus 1 and 2. Slack bus 5, 6 and 7 satisfy this property. However, the optimum values of bus voltages are the values that are very close to 1 per unit to have minimum line losses. Hence bus 5 is the suitable bus to be selected as slack. Similar result is obtained for grid with distributed generators connected to bus 6 and 7. Figure 4 shows the comparison of the magnitude of bus voltages when bus 5 is slack.

This result is considered a novel investigation to select the optimum slack bus, unlike the analysis given in the literatures which are usually selecting bus 1 as slack.

The number of iterations to reach the accuracy of Gauss method is given in Figure 5. It can be seen from Figures 4 and 5 that the values are almost the same in bus 1 to bus 4, but are different in bus 6 and 7 since they are the distribution buses.

The analysis is processed to evaluate the bus current and the generator voltages $\mathrm{E}=$ bus voltage $\mathrm{V}+$ the voltage drops in the transformer and generator impedance. It is illustrated in Figure 6. Current flows in

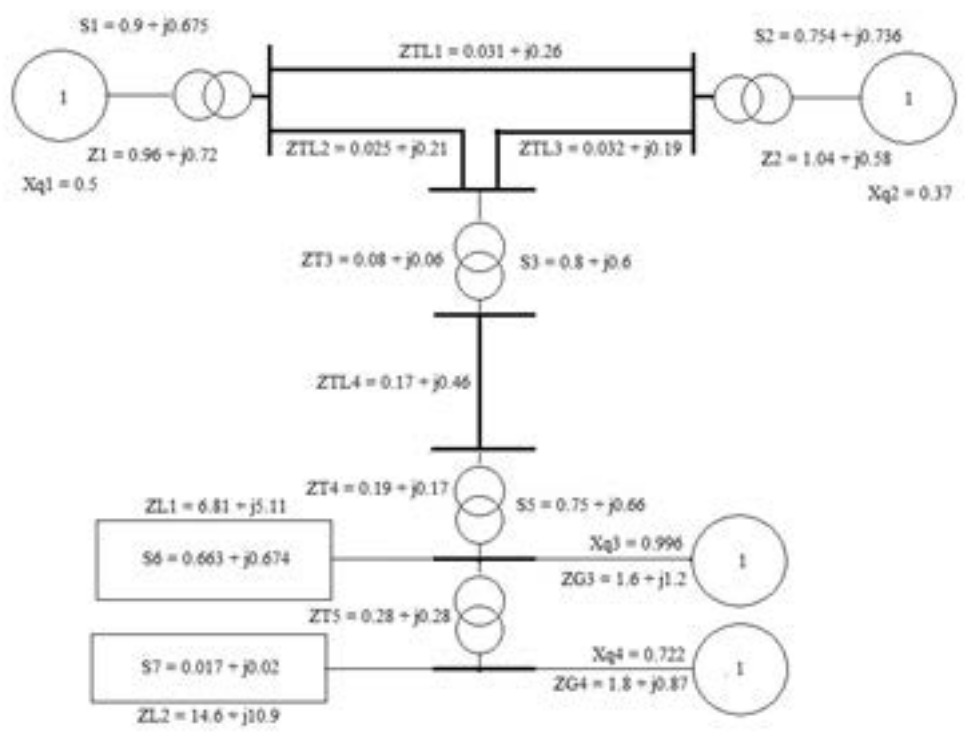

Bus admittance matrix without distributed generator (1)

$\begin{array}{ccccccc}1.68-\mathrm{j} 8.99 & 0.45-\mathrm{j} 3.79 & 0.56-\mathrm{j} 4.7 & 0 & 0 & 0 & 0 \\ 0.45-\mathrm{j} 3.79 & 2.04-\mathrm{j} 9.32 & 0.86-\mathrm{j} 5.12 & 0 & 0 & 0 & 0 \\ 0.56-\mathrm{j} 4.7 & 0.86-\mathrm{j} 5.12 & 9.42-\mathrm{j} 15.82 & 8-\mathrm{j} 6 & 0 & 0 & 0 \\ 0 & 0 & 8-\mathrm{j} 6 & 8.71-\mathrm{j} 7.91 & 0.71-\mathrm{j} 1.91 & 0 & 0 \\ 0 & 0 & 0 & 0.71-\mathrm{j} 1.91 & 3.63-\mathrm{j} 4.53 & 2.92-\mathrm{j} 2.62 & 0 \\ 0 & 0 & 0 & 0 & 2.92-\mathrm{j} 2.62 & 4.8-\mathrm{j} 4.48 & 1.79-\mathrm{j} 1.79 \\ 0 & 0 & 0 & 0 & 0 & 1.79-\mathrm{j} 1.79 & 1.83-\mathrm{j} 1.82\end{array}$

Figure 3: Per unit powers, voltages and impedances.

\begin{tabular}{|c|c|c|c|c|c|c|c|}
\hline Bus & V. 1 & V. 2 & V. 3 & V. 4 & V. 5 & V. 6 & V. 7 \\
\hline Generator 1 & 1 & 1.106 & 1.037 & 1.115 & 1.254 & 1.329 & 1.415 \\
\hline Generator 2 & 1.127 & 1 & 1.045 & 1.123 & 1.263 & 1.338 & 1.426 \\
\hline Transmis. 3 & 1.195 & 1.182 & 1 & 1.097 & 1.269 & 1.360 & 1.465 \\
\hline Transmis. 4 & 1.272 & 1.259 & 1.091 & 1 & 1.229 & 1.347 & 1.482 \\
\hline Transmis. 5 & 1.662 & 1.653 & 1.520 & 1.458 & 1 & 1.238 & 1.504 \\
\hline Distribute 6 & 1.714 & 1.706 & 1.587 & 1.53 & 1.137 & 1 & 1.381 \\
\hline Distribute 7 & 1.668 & 1.660 & 1.543 & 1.48 & 1.096 & 0.958 & 1 \\
\hline
\end{tabular}

Table 1: Bus voltages magnitude with different slack bus for the grid without distributed generators. 


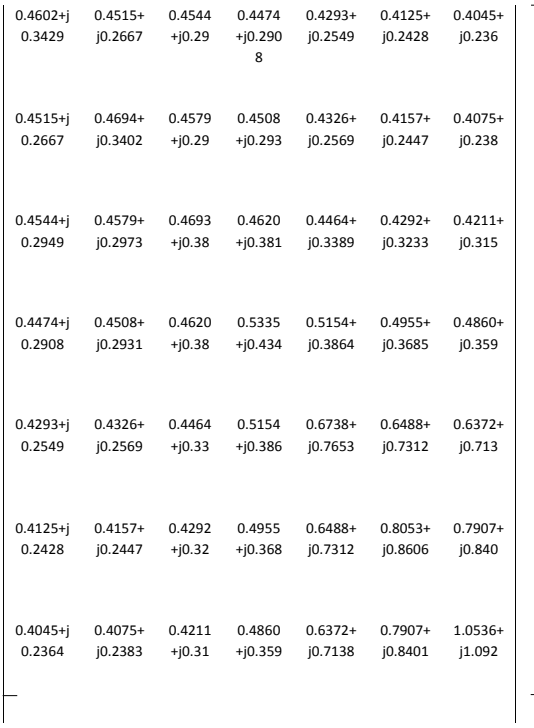

Bus impedance matrix without distributed generator. $\quad$ (2)

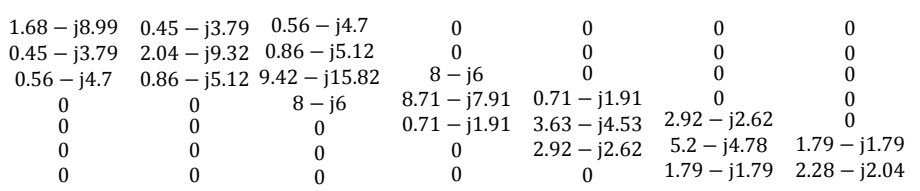

Bus admittance matrix with distributed generator.

(3)

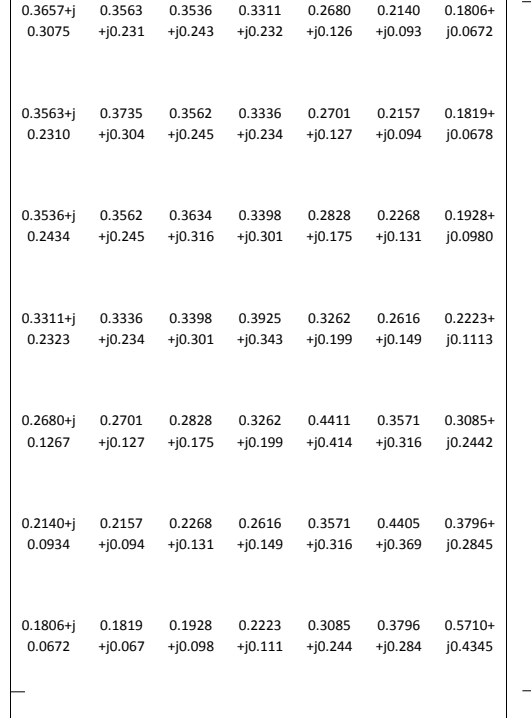

Bus impedance matrix with distributed generator.

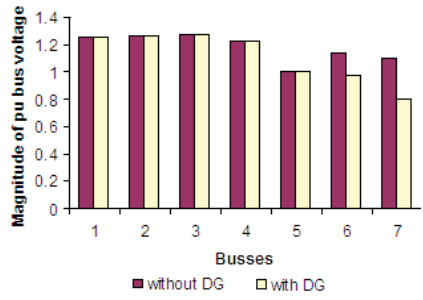

Figure 4: Magnitude of bus voltages at each bus for slack bus 5. 


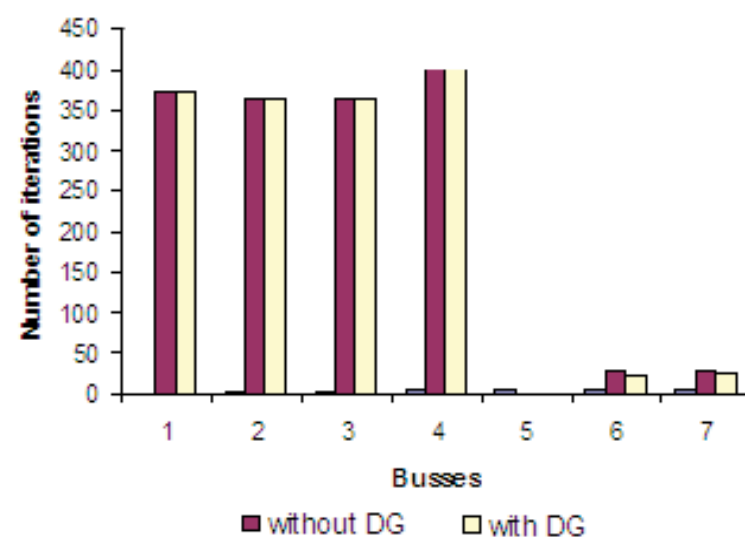

Figure 5: Number of iterations at each bus.

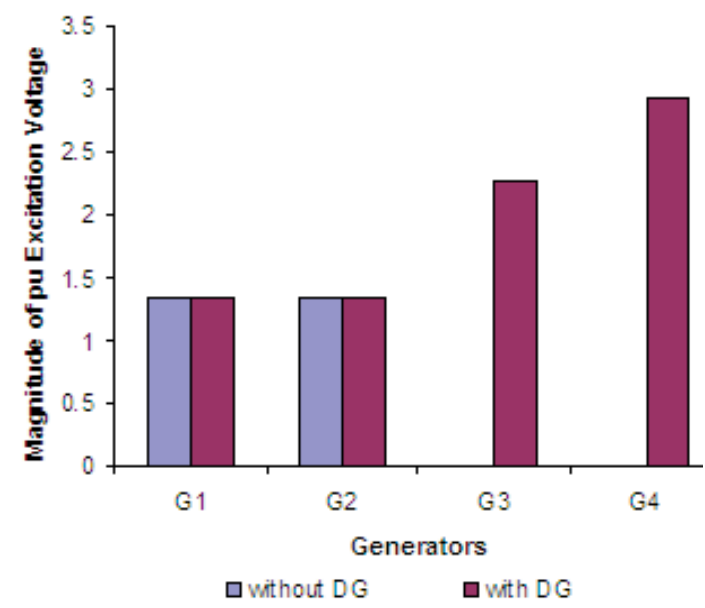

Figure 6: Magnitude of generator voltages at steady-state.

the 4 lines are obtained and the magnitudes of line flow and line loss are shown in Figures 7 and 8 respectively.

It is noted from Figure 8 that the line loss is smaller when selecting bus 5 as slack than selecting another slack bus.

\section{Short Circuit Investigation}

A symmetrical 3-phase fault is used, and the calculation of fault current in each bus is obtained. Figure 9 shows the magnitude of fault currents in both cases using the diagonal of the impedance matrix (2) and (4) with the bus voltages of Figure 4 . The calculation of the transient bus voltages during fault are given in Tables 2 and 3 .

In Figure 9, fault current without distributed generators in power grid network is lower than the fault current with distributed generators. It is clearly indicating that placing distributed generators at bus 6 and 7 causes an increase of the fault current at all buses. This shows that the presence of distribution generators in a network affects the short circuit level of the network. It creates an increase in the fault currents when compared to normal conditions at which no distributed generators is installed in the network. The maximum increase is at bus bar 6 which contributed $75.25 \%$ and this seems to be quite reasonable as the distributed generators is located at this bus. The distance between the distributed generators and the fault is too small and the current is not damped at all. This close distance leads to an increase in the percentage of distributed generators contribution to the fault, consequently increasing the value of fault current. Increase in fault current at other buses is less than that at bus 6 due to the far distance of the fault location from both utility and distributed generators. The second highest fault current reported is with the fault location at bus 5 which has a fault percentage of $68.37 \%$.

Tables 2 and 3 shows the magnitude of bus voltages during fault at each bus for the case of grid with and without solar power injection by using bus 5 as slack. By comparing the magnitude of bus voltage among

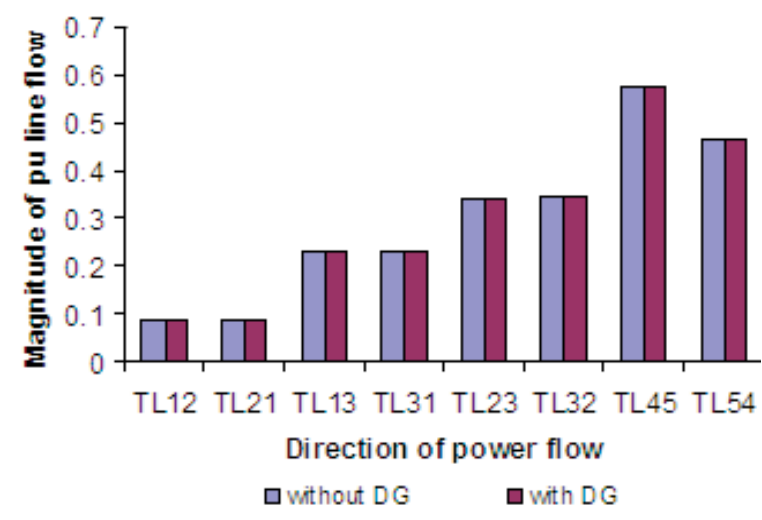

Figure 7: Magnitude of line flow power in per unit.

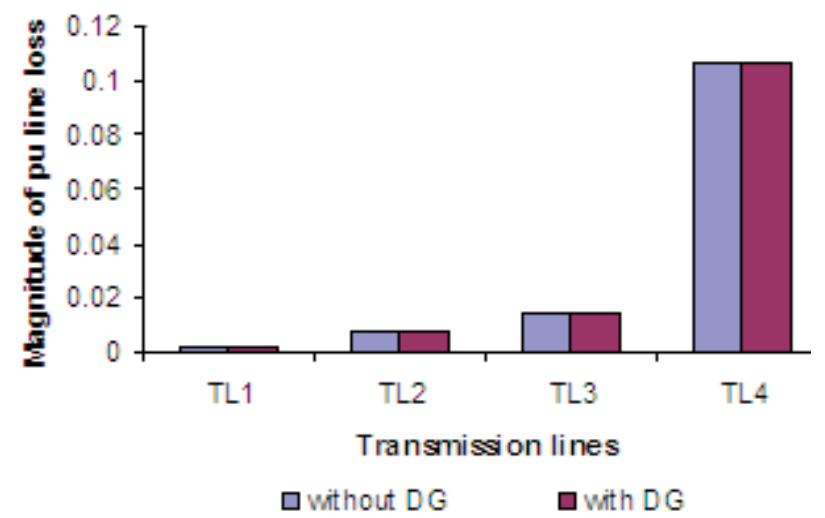

Figure 8: Magnitude of line losses at normal operation.

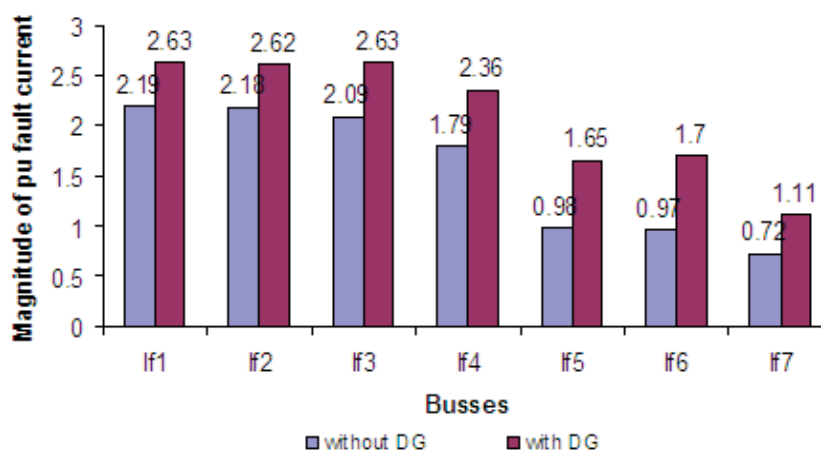

Figure 9: Magnitude of symmetric fault current at each bus. 


\begin{tabular}{|c|c|c|c|c|c|c|c|}
\hline Bus & 1 & 2 & 3 & 4 & 5 & 6 & 7 \\
\hline \multirow{3}{*}{$\begin{array}{c}\text { Fault } \\
\text { Current } \\
\mathrm{I}_{\mathrm{f}}\end{array}$} & 2.19 & 2.18 & 2.09 & 1.79 & 0.98 & 0.97 & 0.72 \\
\hline & & & & & & & \\
\hline & $\angle^{39.12}$ & $L^{-39.0}$ & $\angle \angle^{40.28}$ & $\angle^{38.88}$ & $\angle^{48.6}$ & $\angle-47.9$ & $L^{-47.4}$ \\
\hline \multirow{2}{*}{ V1 } & 0 & 0.17 & 0.16 & 0.31 & 0.79 & 0.82 & 0.93 \\
\hline & $\angle 0$ & $\angle 43.32$ & $\beta 4.47$ & $\angle^{8.21}$ & $\angle Z .07$ & $\angle^{6.03}$ & $\angle 2.85$ \\
\hline \multirow{2}{*}{ V2 } & 0.16 & 0 & 0.15 & 0.31 & 0.80 & 0.82 & 0.94 \\
\hline & $\angle 38.24$ & $\angle 0$ & $\angle 29.75$ & $\angle^{5.31}$ & $\not 5.95$ & $\angle 4.94$ & $\angle 1.89$ \\
\hline \multirow{2}{*}{ V3 } & 0.14 & 0.14 & 0 & 0.20 & 0.74 & 0.77 & 0.90 \\
\hline & $\angle 49.95$ & $\angle 51.67$ & $\angle 0$ & $\angle^{-8.45}$ & ¿ .14 & $\angle 7.14$ & $\angle 6.12$ \\
\hline \multirow{2}{*}{ V4 } & 0.15 & 0.15 & 0.03 & 0 & 0.63 & 0.66 & 0.81 \\
\hline & $\angle 61.99$ & $\angle 63.92$ & $\angle 132.1$ & $\angle 0$ & $\angle 2.5$ & $\perp^{2.51}$ & $\angle 0.87$ \\
\hline \multirow{2}{*}{ V5 } & 0.18 & 0.18 & 0.18 & 0.16 & 0 & 0.06 & 0.31 \\
\hline & $\angle 116.4$ & $\angle 118.0$ & $\angle 159.5$ & $\angle 164.8$ & $\angle 0$ & $\angle ־ 7.15$ & $\angle-1.86$ \\
\hline \multirow{2}{*}{ V6 } & 0.17 & 0.17 & 0.05 & 0.04 & 0.18 & 0 & 0.30 \\
\hline & $\angle 52.86$ & $\angle 54.23$ & $\angle 67.65$ & $\beta 1.32$ & $\angle 5.69$ & $\angle 0$ & $\angle-2.18$ \\
\hline \multirow{2}{*}{ V7 } & 0.16 & 0.15 & 0.04 & 0.03 & 0.16 & 0.02 & 0 \\
\hline & $\angle 57.2$ & $\angle 58.84$ & $\angle 89.56$ & $\angle 47.12$ & $\angle 7.21$ & $L^{-173}$ & $\angle 0$ \\
\hline
\end{tabular}

Table 2: Fault current and transient bus voltage at each bus for the case of grid without distributed generators.

\begin{tabular}{|c|c|c|c|c|c|c|c|}
\hline Bus & 1 & 2 & 3 & 4 & 5 & 6 & 7 \\
\hline $\begin{array}{c}\text { Fault } \\
\text { Current } \\
\mathrm{I}_{\mathrm{f}}\end{array}$ & $\begin{array}{r}2.63 \\
\angle-42.5\end{array}$ & $\begin{array}{r}2.62 \\
\angle-42.3\end{array}$ & $\begin{array}{r}2.63 \\
\angle-41.8\end{array}$ & $\begin{array}{r}2.36 \\
\angle-40.9\end{array}$ & $\begin{array}{r}1.65 \\
\angle-43.2\end{array}$ & $\begin{array}{r}1.70 \\
\angle-42.8\end{array}$ & $\begin{array}{c}1.11 \\
\angle-43.19\end{array}$ \\
\hline V1 & $\begin{array}{r}0 \\
\angle 0\end{array}$ & $\begin{array}{r}0.20 \\
\angle 39.6\end{array}$ & $\begin{array}{c}0.16 \\
\angle 4.47\end{array}$ & $\begin{array}{r}0.31 \\
\angle 8.21\end{array}$ & $\begin{array}{r}0.79 \\
\angle 7.07\end{array}$ & $\begin{array}{r}0.88 \\
\angle 5.04\end{array}$ & $\begin{array}{r}1.06 \\
\angle 1.60\end{array}$ \\
\hline V2 & $\begin{array}{r}0.20 \\
\angle 5.38\end{array}$ & $\begin{array}{r}0 \\
\angle 0\end{array}$ & $\begin{array}{r}0.15 \\
\angle 29.75\end{array}$ & $\begin{array}{r}0.31 \\
\angle 5.31\end{array}$ & $\begin{array}{r}0.80 \\
\angle 5.95\end{array}$ & $\begin{array}{r}0.89 \\
\angle 4.03\end{array}$ & $\begin{array}{r}1.06 \\
\angle 0.76\end{array}$ \\
\hline V3 & $\begin{array}{c}0.21 \\
\not 2.11\end{array}$ & $\begin{array}{r}0.20 \\
\angle 43.1\end{array}$ & $\begin{array}{r}0 \\
\angle 0\end{array}$ & $\begin{array}{r}0.20 \\
\angle-8.45\end{array}$ & $\begin{array}{r}0.74 \\
\angle 7.14\end{array}$ & $\begin{array}{r}0.84 \\
\angle 7.14\end{array}$ & $\begin{array}{r}1.04 \\
\angle 5.52\end{array}$ \\
\hline V4 & $\begin{array}{c}0.23 \\
\angle 39.28\end{array}$ & $\begin{array}{r}0.22 \\
\angle 40.0\end{array}$ & $\begin{array}{r}0.04 \\
\angle 20.76\end{array}$ & $\begin{array}{r}0 \\
\angle 0\end{array}$ & $\begin{array}{r}0.63 \\
\angle 2.51\end{array}$ & $\begin{array}{r}0.74 \\
\angle 2.51\end{array}$ & $\begin{array}{r}0.97 \\
\angle 9.50\end{array}$ \\
\hline V5 & $\begin{array}{r}0.35 \\
\angle 1.91\end{array}$ & $\begin{array}{r}0.34 \\
\angle 42.4\end{array}$ & $\begin{array}{c}0.21 \\
\angle 48.18\end{array}$ & $\begin{array}{r}0.19 \\
\Sigma^{53.06}\end{array}$ & $\begin{array}{r}0 \\
\angle 0\end{array}$ & $\begin{array}{r}0.19 \\
\angle 5.59\end{array}$ & $\begin{array}{r}0.57 \\
\angle 3.72\end{array}$ \\
\hline V6 & $\begin{array}{r}0.42 \\
\angle 20.89\end{array}$ & $\begin{array}{r}0.42 \\
\angle 21.0\end{array}$ & $\begin{array}{c}0.31 \\
\angle 17.23\end{array}$ & $\begin{array}{r}0.29 \\
\angle 7.78\end{array}$ & $\begin{array}{r}0.19 \\
\angle-7.48\end{array}$ & $\begin{array}{r}0 \\
\angle 0\end{array}$ & $\begin{array}{r}0.45 \\
\angle 1.25\end{array}$ \\
\hline V7 & $\begin{array}{r}0.34 \\
\angle 18.4\end{array}$ & $\begin{array}{r}0.34 \\
\angle 18.6\end{array}$ & $\begin{array}{r}0.25 \\
\angle 4.94\end{array}$ & $\begin{array}{r}0.23 \\
\angle 5.57\end{array}$ & $\begin{array}{r}0.15 \\
\angle-10.5\end{array}$ & $\begin{array}{r}0.008 \\
\angle 67.4\end{array}$ & $\begin{array}{r}0 \\
\angle 0\end{array}$ \\
\hline
\end{tabular}

Table 3: Fault current and transient bus voltage at each bus for the case of grid with distributed generators. all the bus, bus voltages nearby the bus bar which fault occurs will be increased whereas bus bar which is far apart to the fault also increases when injection the distributed generators. As the distance between the bus bar and the fault location increases the value of the bus voltage increases.

The generator excitation voltage values during transient state are changed according to the location of the fault. Thus, for a fault at each bus, excitation voltages of the 4 generators have different values. Figure 10 shows the generator voltage values in per unit when the fault occurs at bus 1 in the 2 cases.

Current flow, line flow and line losses are also calculated in each

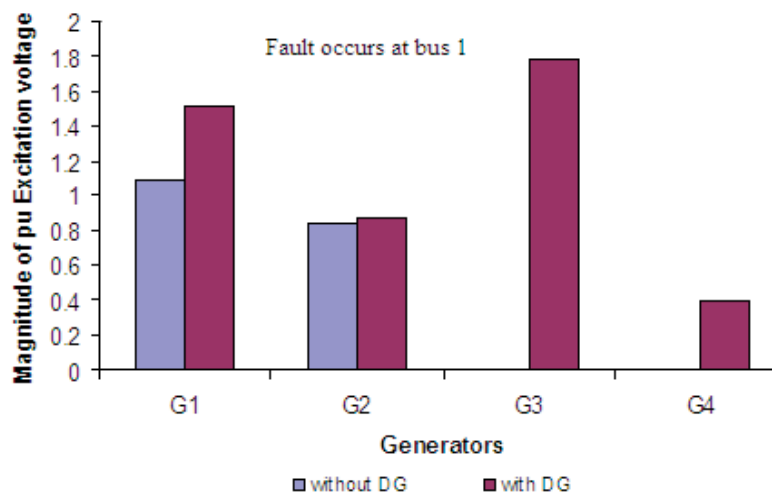

Figure 10: Magnitude of generator voltages at transient

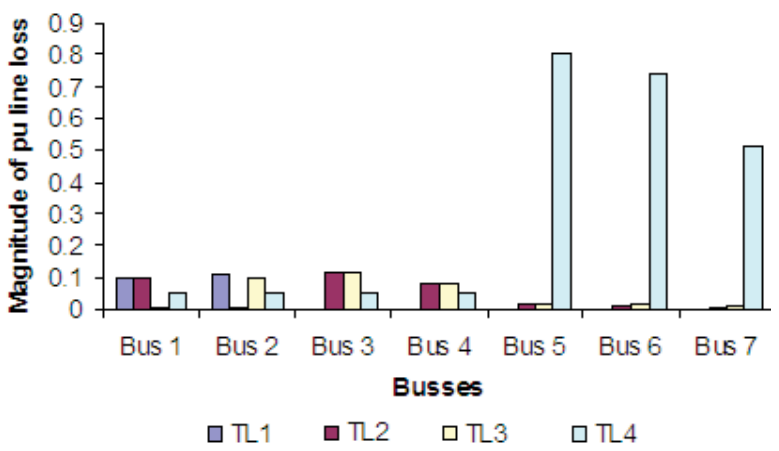

Figure 11: Line loss for a grid without DG using bus 5 as slack.

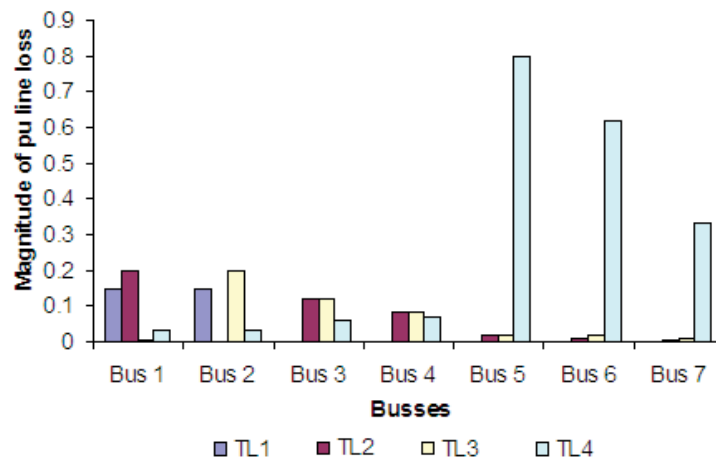

Figure 12: Line loss for a grid with DG using bus 5 as slack. 
Citation: Barsoum N, Asok C, Kwong D, Kit CT (2017) Power Analysis for a Limited Bus Grid System with Distribution Generators. Global J Technol Optim 8: 216doi: 10.4172/2229-8711.1000216

Page 7 of 10

transmission line when the fault occurs at each bus. Figures 11 and 12 illustrate the line loss in the 4 lines at each bus fault occurrence.

The figures show the magnitude of line loss in each transmission lines during fault at each bus for the case of grid with and without distributed generators by using bus 5 as slack. By comparing the power loss at bus 5, 6 and 7, the magnitude of power loss is observed to decrease when there is additional generators which is important to achieve a better reliability of the system with reduced losses. Normally, it is assumed that losses decrease when generation takes place closer to the load site. According to [8], researchers concluded that solar power injection reduces the transmission losses but Figure 12 shows that locating distributed generators will be minimizing power losses at bus [5-7] and maximizing power losses at bus [1-4]. By comparing the power loss at bus 3, 4 there are slightly increase on power loss for each transmission line. This indicates that there is effect on power loss when at bus 3, 4 in case of with DG. Power loss will be significant decrease when the transmission line is closer to the location of DG and slightly increase when the location of distributed generators is far away. When fault occurs at bus 5, power loss is highest for the 2 cases. This indicates that protection devices need to be considered to reduce power loss. When a short to earth or power loss is greater than 0.1 per unit MVA occurs, protection is needed to disconnect all the equipment to save all lines. Impedance relay can be used for protection the transmission line. When a fault appears on the transmission line, the impedance setting in the relay is compared to the apparent impedance of the transmission line from the relay terminals to the fault. If the relay setting is determined to be below the apparent impedance it is determined that the fault is within the zone of protection.

\section{Results}

Stability can be determined by the power-angle formula (5) at both steady-state and transient. The power angle has 3 values, 2 at pre-fault (the initial $\delta_{\mathrm{o}}$ and maximum $\delta_{\mathrm{m}}$ ) and one at transient (the critical $\delta_{\mathrm{cr}}$ ). Critical angle is calculated at each bus when the fault occurs at any of the 7 buses and as referred to one of the 4 generators. Values given in Tables 2 and 3, impedances (2), (4) and Figures 4, 7 and 10 are involved in the analysis.

$$
\begin{array}{lc}
P_{i}=\frac{E_{i} V_{j}}{X_{T j}} \sin \delta+\frac{V_{j}^{2}\left(X_{T j}-X_{q i}\right)}{2 X_{T j} X_{q i}} \sin 2 \delta & \text { pre }- \text { fault } \\
P_{i}^{\prime}=\frac{E_{i}^{\prime} V_{j}^{\prime}}{X_{T j}^{\prime}} \sin \delta+\frac{V_{j}^{\prime 2}\left(X_{T j}^{\prime}-X_{q i}\right)}{2 X_{T j}^{\prime} X_{q i}} \sin 2 \delta & \text { transient }
\end{array}
$$

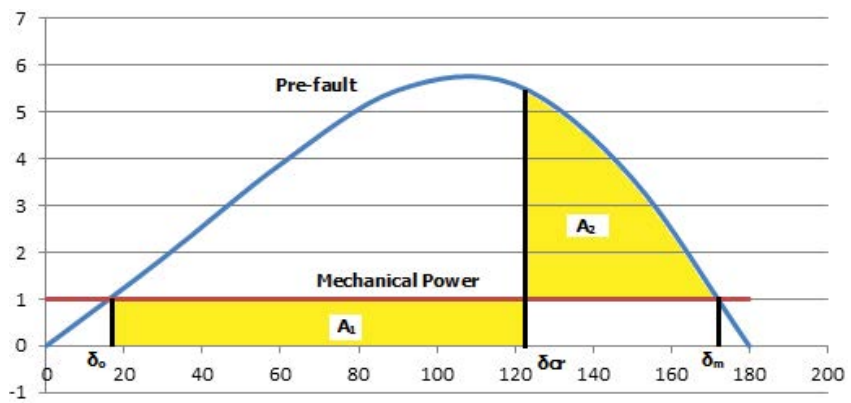

Figure 13: $P$ and $P^{\prime}$ curves when the fault occurs at the same bus.

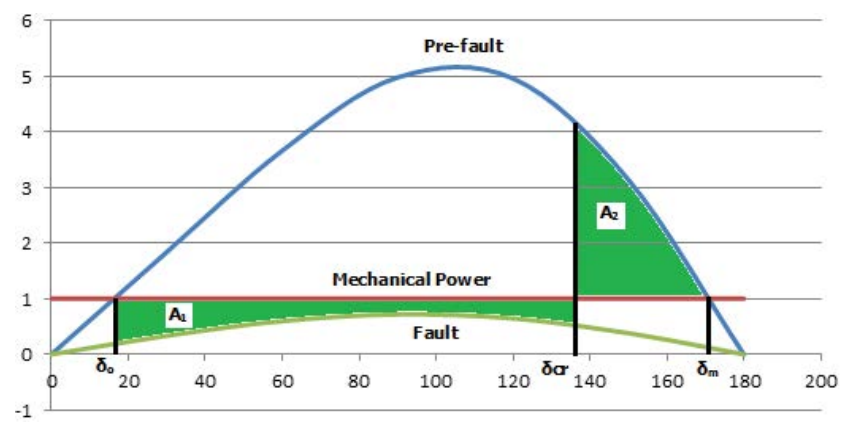

Figure 14: $P$ and $P$ ' curves when the fault occurs at different bus.

\begin{tabular}{|c|c|c|c|c|c|c|c|}
\hline Bus & $\mathbf{1}$ & $\mathbf{2}$ & $\mathbf{3}$ & $\mathbf{4}$ & $\mathbf{5}$ & $\mathbf{6}$ & $\mathbf{7}$ \\
\hline 1 & 122.7 & 138.4 & 138.2 & 170 & & & \\
\hline 2 & 137.7 & 123.3 & 137.3 & 163.6 & & & \\
\hline 3 & 128.7 & 128.7 & 117.4 & 128.2 & & & \\
\hline 4 & 120.5 & 120.5 & 111.5 & 109.8 & & & \\
\hline 5 & 68.2 & 68.2 & 68.2 & 67.5 & 63 & 81.1 & 70.4 \\
\hline 6 & 81.5 & 64.6 & 61.2 & 68 & 65.1 & 60.9 & 63.7 \\
\hline 7 & 52.6 & 52.9 & 50.9 & 50.7 & 52.2 & 49.1 & 50.4 \\
\hline
\end{tabular}

Table 4: Critical angle at each bus as referred to G1, without DG.

\begin{tabular}{|c|c|c|c|c|c|c|c|}
\hline Bus & $\mathbf{1}$ & $\mathbf{2}$ & $\mathbf{3}$ & $\mathbf{4}$ & $\mathbf{5}$ & $\mathbf{6}$ & $\mathbf{7}$ \\
\hline 1 & 116.8 & 129.3 & 128.4 & 145 & & & \\
\hline 2 & 129 & 117.6 & 128 & 144.8 & & & \\
\hline 3 & 118.4 & 118.4 & 110.2 & 123.3 & & & \\
\hline 4 & 110.6 & 110.6 & 102 & 101.4 & 128.2 & & \\
\hline 5 & 63.1 & 63.1 & 63.1 & 62.5 & 60 & 60.7 & 69.3 \\
\hline 6 & 62 & 62 & 60 & 60.1 & 62.2 & 60.13 .8 & 64.7 \\
\hline 7 & 56.2 & 55 & 54.1 & 54 & 55.4 & 51.4 & 51.5 \\
\hline
\end{tabular}

Table 5: Critical angle at each bus as referred to G2, without DG.

\begin{tabular}{|c|c|c|c|c|c|c|c|}
\hline Bus & $\mathbf{1}$ & $\mathbf{2}$ & $\mathbf{3}$ & $\mathbf{4}$ & $\mathbf{5}$ & $\mathbf{6}$ & $\mathbf{7}$ \\
\hline 1 & 127.2 & & 163.3 & & & & \\
\hline 2 & 165.8 & 127.9 & 156.6 & & & & \\
\hline 3 & 166.3 & 161.8 & 126.4 & 161.8 & & & \\
\hline 4 & 164.7 & 159.4 & 126.2 & 121.8 & & & 164.7 \\
\hline 5 & & & 136 & 131 & 104 & 130.9 & \\
\hline 6 & & & & & 147.7 & 109.2 & \\
\hline 7 & & & 151.8 & 137 & 113.9 & 91.6 & 74.9 \\
\hline
\end{tabular}

Table 6: Critical angle at each bus as referred to $\mathrm{G} 1$ and with DG.

\begin{tabular}{|c|c|c|c|c|c|c|c|}
\hline Bus & $\mathbf{1}$ & $\mathbf{2}$ & $\mathbf{3}$ & $\mathbf{4}$ & $\mathbf{5}$ & $\mathbf{6}$ & $\mathbf{7}$ \\
\hline 1 & 122.6 & 139.2 & 135 & 154.6 & & & \\
\hline 2 & 139.6 & 123.2 & 134.7 & 154.3 & & & \\
\hline 3 & 138.2 & 137.3 & 121.5 & 136 & & & \\
\hline 4 & 133.7 & 132.7 & 118.5 & 116 & & & \\
\hline 5 & 110.7 & 110 & 99.5 & 125 & 97.1 & 125 & 152.5 \\
\hline 6 & & & 138.5 & 134.7 & 120.1 & 103.5 & \\
\hline 7 & 119 & 119 & 105.6 & 103.1 & 95.5 & 85.5 & 85.5 \\
\hline
\end{tabular}

Table 7: Critical angle at each bus as referred to $G 2$ and with DG.

Where the subscripts, $i=1,2,3,4, j=1,2, \ldots, 7$

$P_{i}$ is the mechanical turbine power at steady-state $=1$ per unit.

Equal area criterion is applied to obtain the critical stability which relates to the critical clearing angle. Figures 13 and 14 are example of 
Citation: Barsoum N, Asok C, Kwong D, Kit CT (2017) Power Analysis for a Limited Bus Grid System with Distribution Generators. Global J Technol Optim 8: 216doi: 10.4172/2229-8711.1000216

\begin{tabular}{|c|c|c|c|c|c|c|c|}
\hline Bus & $\mathbf{1}$ & $\mathbf{2}$ & $\mathbf{3}$ & $\mathbf{4}$ & $\mathbf{5}$ & $\mathbf{6}$ & $\mathbf{7}$ \\
\hline 1 & 134 & & 164.5 & & & & \\
\hline 2 & & 140.2 & 161.8 & & & & \\
\hline 3 & & 145 & 143.7 & 155 & & & \\
\hline 4 & & & 140.5 & 136.5 & & & \\
\hline 5 & & & 156 & 151 & 124.7 & 151.1 & \\
\hline 6 & & & & & 166.2 & 127.6 & \\
\hline 7 & & & & 166.9 & 138.1 & 115.4 & 114.8 \\
\hline
\end{tabular}

Table 8: Critical angle at each bus as referred to $G 3$ and with DG.

\begin{tabular}{|c|c|c|c|c|c|c|c|}
\hline Bus & $\mathbf{1}$ & $\mathbf{2}$ & $\mathbf{3}$ & $\mathbf{4}$ & $\mathbf{5}$ & $\mathbf{6}$ & $\mathbf{7}$ \\
\hline 1 & 142.6 & 146.9 & 146 & 147.9 & 168.2 & 173.3 & \\
\hline 2 & 148.6 & 143 & 147.4 & 151.2 & 150.2 & & \\
\hline 3 & 146.6 & 146.4 & 142.3 & 146.4 & 162.5 & 168.8 & \\
\hline 4 & 141.1 & 143.9 & 140.4 & 139.1 & 153.9 & 157.5 & 171.8 \\
\hline 5 & 135.9 & 135.8 & 133.2 & 132.8 & 129.1 & 132.8 & 140.9 \\
\hline 6 & 142.4 & 142.4 & 141.2 & 138.8 & 136.3 & 131.8 & 141.1 \\
\hline 7 & 128.5 & 128.5 & 126.4 & 125.9 & 124.1 & 120.5 & 120.7 \\
\hline
\end{tabular}

Table 9: Critical angle at each bus as referred to $G 4$ and with DG.

\begin{tabular}{|c|c|c|c|c|c|c|c|}
\hline Bus & $\mathbf{1}$ & $\mathbf{2}$ & $\mathbf{3}$ & $\mathbf{4}$ & $\mathbf{5}$ & $\mathbf{6}$ & $\mathbf{7}$ \\
\hline $\mathrm{I}_{\mathrm{f}} \mathrm{pu}$ & 2.18 & 2.19 & 2.09 & 1.79 & 0.98 & 0.97 & 0.72 \\
\hline $\mathrm{I}_{\mathrm{f}} \mathrm{A}$ & 2289 & 2299 & 2194 & 3915 & 2143 & 2828 & 1575 \\
\hline $\mathrm{t}_{\mathrm{cr}}$ & 0.852 & 0.856 & 0.825 & 0.784 & 0.516 & 0.527 & 0.436 \\
\hline
\end{tabular}

Table 10: Per unit fault current and critical time at each bus.

the equal area. Figure 13 shows the areas in a certain bus when the fault occurs at the same bus, where $P^{\prime}=0$ since its bus voltage drops to 0 , while Figure 14 shows the areas as related to another bus, where $P^{\prime} \neq 0$, since its bus voltage drops to a certain value.

Critical angle is obtained in degree by trial and error or MATLAB code taking several iterations for an accurate result. Tables 5-10 present the values obtained for the critical clearing angles in each bus due to fault occurs at each bus for the cases of without and with distributed generators as referred to each of the 4 generators. The empty slots indicate that the angle is indeterminate in which the power-angle curve at transient is closed to the steady-state curve, where the areas are undefined and thus the system shows that the stability is performed, since the generator is not swinging. At these cases, there is no critical angle since it may exceed the 180 degrees and the initial angle at transient is approximately equals the initial angle at steady-state. Figure 15 illustrate this case.

It can be recognized from results in Tables 5 and 6 that when the distributed load bus 6,7 have no generators connected the chance of instability occur in the power stations generators 1 and 2 is high since the critical angle in bus [5-7] are low for any fault can occur at any bus. But when connecting the distributed generators to bus 6 and 7 , the critical angles increase at these buses from the results of Tables 7 and 8 , which means that the stability is improved for generators 1 and 2 , although the fault currents are high in these buses as compared to without distributed generators case. For the results of Tables 9 and 10 it is believed that the distributed generators 3, 4 are seems to be stables for any fault can occur at nay bus since the values of critical angle is moderate.

This stability results with distributed generators are not found in the literatures and therefore it is considered a new discovery.

Critical clearing time can therefore be found from the form (6)

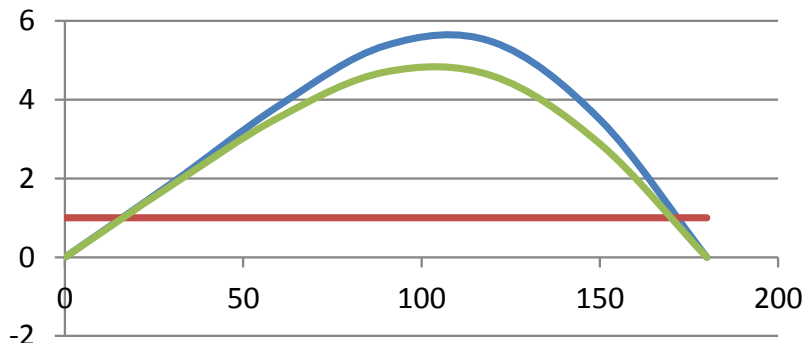

Figure 15: $P$ and $P^{\prime}$ curves at bus 3 when fault occurs at bus 5 .

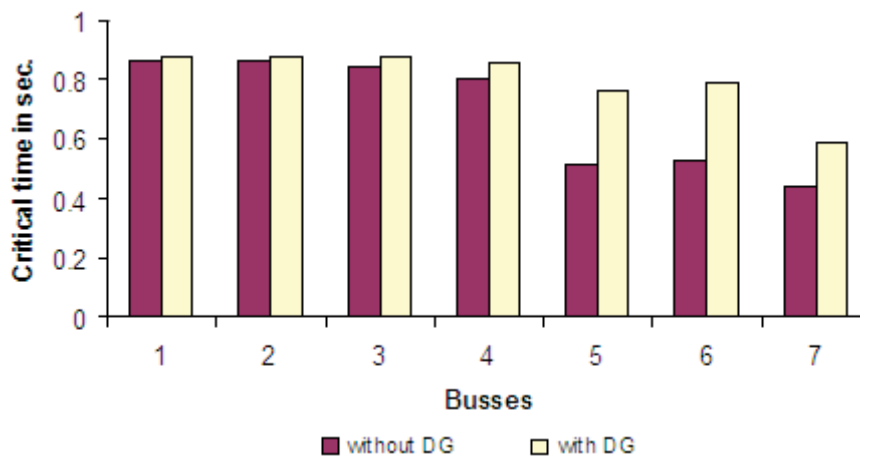

Figure 16: Critical time in each bus as referred to $\mathrm{G} 1$.

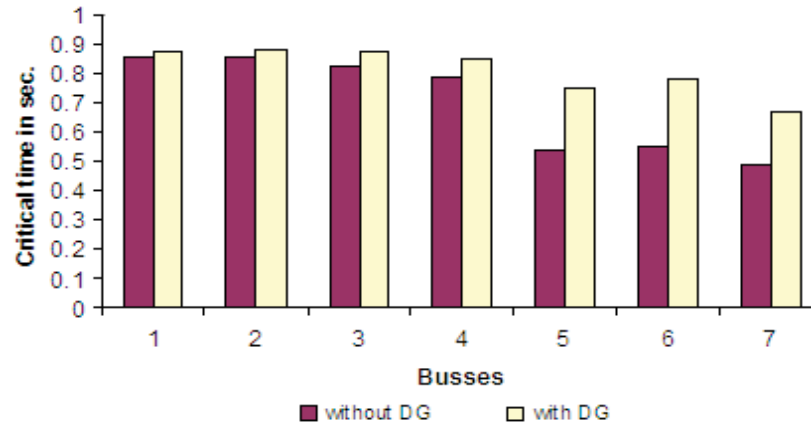

Figure 17: Critical time in each bus as referred to $\mathrm{G} 2$.

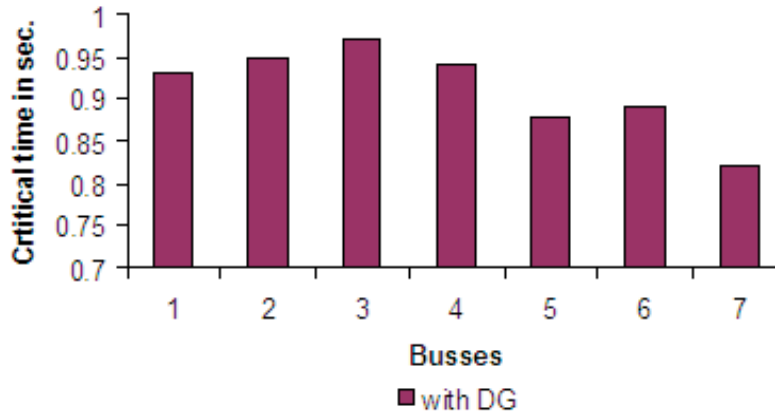

Figure 18: Critical time in each bus as referred to $G 3$. 
Citation: Barsoum N, Asok C, Kwong D, Kit CT (2017) Power Analysis for a Limited Bus Grid System with Distribution Generators. Global J Technol Optim 8: 216doi: 10.4172/2229-8711.1000216

Page 9 of 10

which gives the maximum clearing time before instability and is used as the operating time in the over current relay to obtain the multiple time setting. Figures 16-19 show the critical time values in second in each bus as referred to the generators.

$$
t_{c r}=\sqrt{\frac{2 \mathrm{~J}\left(\delta_{c r}-\delta_{o}\right) \pi}{180 P_{i}}}
$$

where $J$ is the moment of inertia which is assumed to be 2 per unit and $\delta_{\mathrm{o}}$ is the initial angle calculated from the pre-fault form of (5).

It is seen that when the distributed generators are injected in the load busses the critical time increased in all busses which indicates that it gives more time to clear before instability. This states that grid with distributed generators is more stable than the grid without distributed generators, although the fault currents are much higher.

\section{Protection}

This section determines the selection of current transformers for over current relays types $\mathrm{CO} 8, \mathrm{CO} 9$ and $\mathrm{CO} 11$, which relates to standard inverse SI, very inverse VI and extremely inverse EI, respectively. This is followed by calculating time multiple setting TMS and current settings of the relay at each bus considering the optimum fault currents and operating times are the minimum values given in Figures 9, 15 and 16. Table 11 summarizes the per unit currents, actual current in Amper and operating times in sec.

The base currents are calculated from the base voltage at each bus and 500 MVA base powers using the formula (7)

$$
S=\sqrt{3} V_{i} I^{*}, i=1,2,---, 7
$$

The distributed bus 6, 7 are protected from the feeders, 3 feeders connected to bus 6 and 20 to bus 7 .

Current transformers therefore, can be selected based on the values of actual fault current given in table 11. Pick up current $I_{p}$ and current settings as well as the time multiple setting for each relay type are then determined from (8) and given in Tables 12 and 13.

$$
\begin{aligned}
& \text { ST (CO8) } t_{o}=T M S \frac{0.14}{\left(\frac{I_{f}}{I_{p}}\right)^{0.02}-1} \\
& \text { VI (CO9) } t_{o}=T M S \frac{13.5}{\left(\frac{I_{f}}{I_{p}}\right)-1} \\
& \text { EI (CO11) } t_{o}=T M S \frac{80}{\left(\frac{I_{f}}{I_{p}}\right)^{2}-1}
\end{aligned}
$$

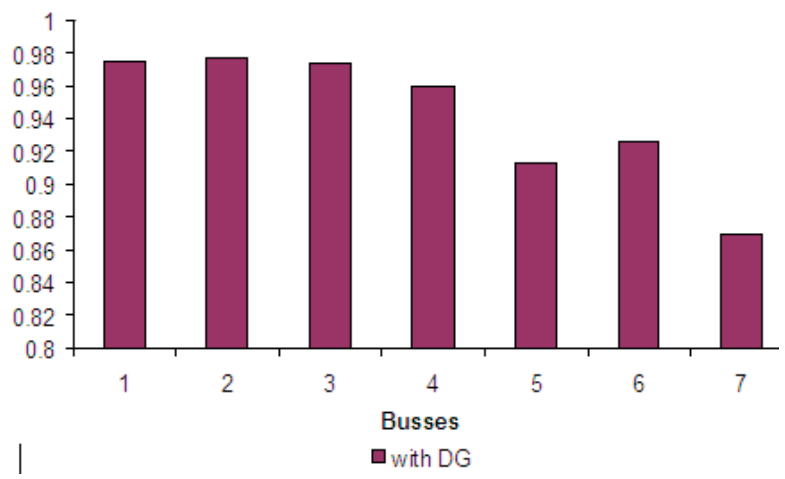

Figure 19: Critical time in each bus as referred to $\mathrm{G} 4$.

\begin{tabular}{|c|c|c|c|c|c|c|c|}
\hline Bus & $\mathbf{1}$ & $\mathbf{2}$ & $\mathbf{3}$ & $\mathbf{4}$ & $\mathbf{5}$ & $\mathbf{6}$ & $\mathbf{7}$ \\
\hline $\mathrm{CT}$ & $2000 / 5$ & $2000 / 5$ & $2000 / 5$ & $4000 / 5$ & $2000 / 5$ & $2500 / 5$ & $1500 / 5$ \\
\hline $\mathrm{I}_{\mathrm{f}} \mathrm{P}$ & 5.7225 & 5.7475 & 5.485 & 4.8937 & 5.3575 & 5.656 & 5.25 \\
\hline $\mathrm{SI}$ & 3.9432 & 3.9338 & 4.0431 & 4.3385 & 4.1008 & 3.9703 & 4.1517 \\
\hline $\mathrm{VI}$ & 2.8586 & 2.8436 & 3.0100 & 3.4671 & 3.0981 & 2.8995 & 3.1764 \\
\hline $\mathrm{EI}$ & 2.5199 & 2.4974 & 2.7505 & 3.4861 & 2.8878 & 2.5814 & 3.0117 \\
\hline
\end{tabular}

Table 11: Current transformer settings in each bus and relay type.

\begin{tabular}{|c|c|c|c|c|c|c|c|}
\hline Bus & $\mathbf{1}$ & $\mathbf{2}$ & $\mathbf{3}$ & $\mathbf{4}$ & $\mathbf{5}$ & $\mathbf{6}$ & $\mathbf{7}$ \\
\hline $\mathrm{SI}$ & 0.216 & 0.217 & 0.204 & 0.181 & 0.126 & 0.133 & 0.105 \\
\hline $\mathrm{VI}$ & 0.298 & 0.301 & 0.274 & 0.226 & 0.167 & 0.182 & 0.137 \\
\hline $\mathrm{EI}$ & 0.338 & 0.343 & 0.3 & 0.225 & 0.179 & 0.204 & 0.145 \\
\hline
\end{tabular}

Table 12: TMS sec. in each relay.

By this setting relays will trip before critical time when a symmetric fault occurs at its bus.

\section{Conclusion}

A detailed analysis and computation are presented in this paper for load flow, short circuit, stability and protection by taking a simple example of a limited 7-bus power grid system in 2 cases, without and with distributed generators. Calculations of bus voltages at steadystate and transient with fault current at each bus are investigated and compared by Gauss method and impedance matrix in per unit values. Stability analysis based on power-angle characteristics and equal area criterion to calculate the critical load angle and critical clearing time for the 2 cases is given for each bus when a symmetric 3-phase fault occurs at each bus. These is followed by selecting suitable current transformers and setting the current and time multiple setting of three types of over current relays that are set to trip at critical stability time to protect the system.

Optimum values of bus voltages are determined to select a suitable slack bus that gives lower power loss in the grid. The results show that injecting distributed generators don't have any negative impact on the grid, but help to reserve the energy consumption in the load bus. Moreover, distributed generators make the grid system more stable. This is because of the increasing value of critical clearing angle in the result of with distributed generators in most of busses for any fault location.

However, penetration of any distributed generators into a power grid system causes an increase in the fault level of the network at any fault location. Presence of the distributed generators in a location close to the substation or bus bar causes a decrease in the bus voltage during fault and the bus voltage will be increase for bus bar that is far away from the fault location but the fault current is still increased. As the distance between the bus bar and the fault location increases the value of the bus voltage increases. In the 3-phase fault, the voltages at faulted bus phases dropped to zero during the fault.

\section{Appendix}

Gauss-Seidel bus voltage

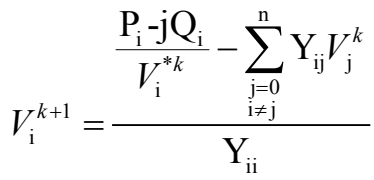

Equal area criteria

$$
A_{1}=P_{m}\left(\delta_{o}-\delta_{c r}\right)-\int_{\delta_{o}}^{\delta_{c r}} P^{\prime} d \delta=A_{2}=\int_{\delta_{c r}}^{\delta_{m}} P d \delta-P_{m}\left(\delta_{m}-\delta_{c r}\right)
$$


Bus current $\quad I_{i}=Y_{n n} V_{i}^{n}$

Fault current $I_{f i}=\frac{V_{i}^{n}}{Z_{i i}}$

Line flow $\mathrm{S}_{\mathrm{ij}}=V_{\mathrm{i}} I_{i j}^{*} \quad \mathrm{~S}_{\mathrm{ji}}=V_{\mathrm{j}} I_{j i}^{*}$

Line Loss $\mathrm{S}_{\mathrm{Lij}}=\mathrm{S}_{\mathrm{ij}}+\mathrm{S}_{\mathrm{ji}}$

Transient bus voltage $V_{i}=1-Z_{i j} I_{f i}$

\section{References}

1. Kundur P, Paserba J, Ajjarapu V, Anderson G, Bose A, et al. (2004) Definition and classification of power system stability. IEEE Transactions on Power Systems 19: 1387-1401.

2. Lee BH, Lee KY (1991) AC study on voltage collapse mechanism in the electric power system. Transactions on Power Systems 6.
3. Tran-Quoc T, Vu-Due T, Feuillet R, Hadjsaid N, Sabonnadire JC, et al., (1998) Dynamic analysis on the voltage instability in the vietnam system. IEEE Catalogue 98EX137.

4. Cutsem TV (2000) Voltage instability: phenomena, countermeasures, and analysis methods. Proceeding of the IEEE 88: 208-227.

5. Nor KM (2013) Renewable distributed generation models in three-phase load flow analysis for smart grid. Indonesian Journal of Electrical Engineering and Computer Science 11: 661-668.

6. Singh M, Mahapatra S (2016) Analysis of symmetrical fault in ieee 14-bus system for enhancing over current protection scheme. International journal of future generation and networking, 9: 51-62.

7. Nallagalva NS, Kirar NK, Agnihotri G (2012) Transient stability analysis of the IEEE 9-bus electric power system. International Journal of Scientific Engineering and Technology 1: 161-166.

8. Barsoum N, Lee CZ (2013) Simulation of power flow and protection of a limited bus grid system with injection solar power. Journal of power and energy engineering 5: 59-69. 